\title{
Analysis of structural, morphological alterations, wettability characteristics and adhesion to enamel after various surface conditioning methods
}

Özcan, Mutlu ; Sadiku, Merita

DOI: https://doi.org/10.1080/01694243.2016.1184411

Posted at the Zurich Open Repository and Archive, University of Zurich ZORA URL: https://doi.org/10.5167/uzh-128076

Journal Article

Accepted Version

Originally published at:

Özcan, Mutlu; Sadiku, Merita (2016). Analysis of structural, morphological alterations, wettability characteristics and adhesion to enamel after various surface conditioning methods. Journal of Adhesion Science and Technology, 30(22):2453-2465.

DOI: https://doi.org/10.1080/01694243.2016.1184411 
Analysis of structural, morphological alterations, wettability characteristics and adhesion to enamel after various surface conditioning methods

\author{
Mutlu Özcan, Dr.med.dent., PhD ${ }^{\mathrm{a}} /$ Merita Sadiku, BDS, MSci ${ }^{\mathrm{b}}$
}

${ }^{a}$ Professor, University of Zurich, Dental Materials Unit, Center for Dental and Oral Medicine, Clinic for Fixed and Removable Prosthodontics and Dental Materials Science, Zurich, Switzerland

${ }^{b}$ Dental Student, University of Zurich, Center for Dental and Oral Medicine, Clinic for Fixed and Removable Prosthodontics and Dental Materials Science, Zurich, Switzerland

Short title: Analysis of various surface conditioning methods on enamel

Correspondance to: Prof. Dr. med. dent. Mutlu Özcan, University of Zürich, Dental Materials Unit, Center for Dental and Oral Medicine Clinic for Fixed and Removable Prosthodontics and Dental Materials Science, Plattenstrasse 11, CH-8032, Zürich, Switzerland. Tel: +41-44-63 45600, Fax: +4144-63 44305. e-mail: mutluozcan@hotmail.com 
Abstract: Minimal invasive dental reconstructions and orthodontic appliances are bonded to enamel without removing the enamel with rotating instruments but the top layer of enamel may be partially aprismatic and impair adhesion. The objectives of this study were to investigate the effect of mechanical surface conditioning methods for removing enamel on its structural, morphological alterations, wettability characteristics and adhesion of resin based cement to the conditioned surfaces. Maxillary human incisors $\left(N=40, n_{\text {quadrant }}=160\right)$ were obtained and coronal sections were embedded in acrylic with their labial surfaces exposed. The teeth were randomly divided into 4 groups and the enamel surface of each tooth was divided into 4 quadrants. The surfaces were conditioned in a clockwise manner by one of the following methods: 1) Non-conditioned enamel acted as the control group (C); 2) Silicone coated disc (Sof-Lex disc, Black, 3M ESPE) (SD); 3) Diamond bur at slow speed (DB) and 4) Air-borne particle abrasion ( $50 \mu \mathrm{m} \mathrm{Al}_{2} \mathrm{O}_{3}, 2$ bar, $5 \mathrm{~s}$ ) (AA). Surface roughness was measured at each quadrant using a non-contact digital profilometer and contact angle measurements were performed using a goniometer. Enamel surfaces were then etched with $37 \% \mathrm{H}_{3} \mathrm{PO}_{4}$ for $60 \mathrm{~s}$ and roughness and wettability measurements were repeated. The enamel surfaces in each quadrant received resin composite luting cement (Variolink II, Ivoclar Vivadent) incrementally in a polyethylene mould (diameter: $1 \mathrm{~mm}^{2}$; height: $4 \mathrm{~mm}$ ) and photopolymerized. The specimens were stored in distilled water for 24 hours at $37^{\circ} \mathrm{C}$ until the testing procedures and then shear force was applied to the adhesive interface until failure occurred in a Universal Testing Machine $(0.5 \mathrm{~mm} / \mathrm{min})$. Microshear bond $(\mu \mathrm{SBS})$ was calculated by dividing the maximum load $(\mathrm{N})$ by the bonding surface area of the resin cement. Representative enamel surfaces were analyzed under the scanning electron microscope (SEM) (x5000) to assess the surface morphology. Failure types were analyzed using optical microscope and SEM. Data (MPa) were analyzed using one-way ANOVA and Tukey`s test for each parameter and Linear model for group comparisons $(\alpha=0.05)$. Surface conditioning method significantly affected the adhesion results $(P<0.001)$, surface roughness $(P=0.017)$ 
and contact angle $(P<0.001)$. Interaction terms were significant $(P>0.05)$. AA (338 \pm 182$)$ created significantly higher surface roughness compared to SD $(308 \pm 180)$ and DB $(242 \pm 197)$ $(P<0.05)$. After etching with $37 \% \mathrm{H}_{3} \mathrm{PO}_{4}, \mathrm{DB}(307 \pm 223)$ resulted in significantly lower roughness than those of SD $(385 \pm 173)$ and AA $(414 \pm 193)(P<0.05)$. AA $(40 \pm 11)$ delivered significantly lower contact angle compared to those of SD $(61 \pm 9)$ and DB $(59 \pm 10)$. After etching with $37 \% \mathrm{H}_{3} \mathrm{PO}_{4}, \mathrm{AA}(42 \pm 10)$ and $\mathrm{DB}(50 \pm 10)$ presented the lowest contact angle $(P<0.05)$. Mean $\mu$ SBS results (MPa) showed significant difference between the experimental groups $(P=0.011)$ and were in descending order as follows: DB $(20 \pm 8)^{\mathrm{a}}<\mathrm{SD}(18 \pm 9)^{\mathrm{a}}<\mathrm{AA}$ $(13 \pm 5)^{b}<C(12 \pm 5)^{b}$. Failure types were predominantly mixed failure type between the enamel and the resin cement with more than half of the resin remained on the enamel surface (32 to 33 out of 40 ) in all groups. Cohesive failure in the enamel was not observed in any of the groups. SEM analysis showed that AA group leaves abundant particles on the enamel surface and after DB and AA, etching could not remove the particles completely and expose the enamel prisms.

Keywords: Adhesion, air-abrasion, enamel, surface conditioning, surface roughness, wettability 


\section{Introduction}

With the advances in adhesive technologies, the dental profession became less invasive. Today, minimal invasive dental reconstructions and orthodontic appliances can be bonded to enamel without removing this tissue with rotating instruments.

Enamel is a crystalline substance that consists of hydroxyapatite arranged in prisms. It is the hardest structure of the body and comprises $96 \mathrm{wt} \%$ inorganic matter, $04-0.8 \mathrm{wt} \%$ organic matter such as proteins, lipids, carbohydrates or lactate and 3.2-3.6 wt\% water [1]. Calcium and phosphate are found in the ratio of $1: 1.2$ as hydroxyapatite minerals in form of small crystals. The histological structure of these hydroxyapatite crystals of enamel in cross section is hexagonal. From lateral perspective, they appear as small rods, of which each is built out of about 100 crystals [2]. They may also appear as prisms. In the centre of the prisms, the crystals are placed parallel to the longitudinal axis and in the outer parts they are almost in $90^{\circ}$ inclination [2]. This change in direction gives the prisms a honeycomb shape structure. The interprismatic areas consist of more loosely packed and randomly oriented crystals surrounded by a higher quantity of water and inorganic matter. That makes the enamel in those areas more susceptible to fluid and ion exchanges, which renders these areas more favourable to remineralisation, yet also more prone to demineralization. The ion exchange can provide good protection against decalcification based on the fact that if hydroxyl ions in the hydroxyapatite are substituted by fluoride-ions, the enamel is rendered more resistant against acids [2].

The success of bonded minimal invasive dental reconstructions and orthodontic appliances to enamel with resin based materials depends highly on the surface characteristics of the enamel [3]. Untreated enamel is generally smooth and non-retentive and covered with a layer of pellicle. When enamel is cut, its surface is also covered with a smear layer created by the rotating instruments. Moreover, the top layer of enamel $20-80 \mu \mathrm{m}$ may be partially aprismatic 
and impair adhesion if not removed [4]. Thus, a subsequent chemical or mechanical conditioning is needed to expose the fresh enamel surface and increase the surface area for further micromechanical retention.

Etching enamel typically with $\mathrm{H}_{3} \mathrm{PO}_{4}$ creates a highly micro-retentive surface, which is easily wetted by hydrophobic resin-based adhesives. The adhesive resin then penetrates the etched surface through capillary action and subsequent polymerization of the resin facilitates micromechanical adhesion. Most commercially available enamel-etching agents have a concentration ranging between $30-40 \%$. When the concentration is less, the dicalcium phosphate dihydrate precipitate forms in the enamel surface which is very difficult to remove by rinsing $[5,6]$. For orthodontic applications, enamel tissue removal is not needed but for some applications in reconstructive dentistry, minimal room has to be created for the material that eventually necessitates the removal of enamel using mechanical methods such as the use of diamond burs, discs or air-borne particle abrasion. All these methods aim to increase the surface area and contribute to micromechanical retention of the resin based material.

The next step after micromechanical roughening of the enamel is the application of the adhesive resin where the conditioned surface provides the foundation for better wettability. Surface wettability indicates the ability of a liquid to wet the surface of a solid $[7,8]$. The wettability of a material is usually determined by measuring the contact angle formed between the substrate and the line tangent to the curved surface of a liquid drop at the point of contact [9]. Contact angle measurement is probably the most popular method to determine the hydrophobicity and/or hydrophilicity of the surfaces of materials. A greater contact angle indicates hydrophobicity, which means a poorer wetting ability of the material. Contact angle of less than $90^{\circ}$ is an indication of a hydrophilic material, whereas a contact angle larger than $90^{\circ}$ indicates a hydrophobic material $[10,11]$. However, surface conditioning of the enamel dictates the measured the contact angle on enamel surfaces and it was reported to be about $50^{\circ}$ for water [10]. 
The objectives of this study therefore, were to investigate the effect of mechanical surface conditioning methods for removing superficial enamel surface on its structural, morphological alterations, wettability characteristics and adhesion of resin based cement. The null hypothesis tested was that mechanical surface conditioning methods would not show difference in roughness, wettability and adhesion of resin composite cement.

\section{Materials and Methods}

Specimen preparation

Schematic description of the experimental design is presented in Fig. 1.

Human maxillary central incisors $\left(\mathrm{N}=40, \mathrm{n}_{\text {quadrant }}=160\right)$ were used in this study. After tissue remnants were removed with a scaler (H6/H7; Hu-Friedy, Chicago, IL), teeth were stored in 0.5\% Chloramin $\mathrm{T}$ for 2 weeks. The roots were removed from the coronal parts using a diamond disc (IsoMet 1000, Buehler Ltd, USA) under water-cooling. The coronal part of teeth were embedded in a polyvinyl chloride (PVC) mould with their labial surfaces exposed using auto-polymerizing acrylic resin (Scandiquick, Scandia, Hagen, Germany).

On each tooth, two lines were drawn mesiodistally and incisoservically and the enamel surfaces were divided into four quadrants with a diamond saw (Well Precision Diamond Wire Saw, Norcross, USA) under slow speed water-cooling.

Initially, surface roughness and contact angle measurements were made from each quadrant. Surface roughness measurement

Surface roughness $(\mathrm{Ra})$ on enamel surfaces was measured using a digital microscope (VHX2000D, Keyence, Osaka, Japan). The scans were obtained from an area of $2 \mathrm{~mm}$ length and 2 $\mathrm{mm}$ width from a pre-established reference point situated in the middle of each specimen at x200.

Contact angle measurement 
One sessile drop of distilled water was applied on the enamel surface at $25^{\circ} \mathrm{C}$ room temperature. Three consecutive contact angle measurements of water were performed using a camera-based goniometer (Easydrop Drop Shape Analysis System, Kruess, Hamburg, Germany) using its corresponding software (Drop Shape Analysis Software for Windows, DSA Version 1.90.0.14). Approximately $0.1 \mu \mathrm{l}$ drop of water was placed on the specimen surface located on a movable table using a micro syringe (diameter: $1.1 \mathrm{~mm}, \mathrm{NE} 42$, Kruess). The drop was illuminated from one side and the camera from the opposite side captured the image of the drop. The image was then transferred to the computer and the contact angle was determined using the software using the Young-Laplace method [12]:

$$
\Delta \rho=0 \cdot\left(\frac{1}{r_{1}}+\frac{1}{r_{2}}\right)
$$

$\Delta p=$

where

$\Delta p$ is the difference in pressure between the outside of the drop and its inside.

r1 and $r 2$ stand fort he principle radii of the curvature.

The specimens were divided into 4 subgroups ( $n_{\text {quadrant }}=10$ per group) to be conditioned with one of the following methods:

Surface conditioning methods

Group C: The non-conditioned enamel surfaces acted as the control group.

Group SD: In this group, the enamel was roughened using a silicone coated disc (Black SofLex Disc, 3M ESPE, Minn, USA) with a contra-angle handpiece (KaVo Gentlepower Lux, Biberach/Riss, Germany) at 100.000 rpm for 5 s under water-cooling. Enamel surfaces were then rinsed with copious water. 
Group DB: A layer of enamel was removed from using a diamond bur of $25 \mu \mathrm{m}$ (Demadent AG, Basssersdorf, Switzerland) with a contra-angle slow speed handpiece (KaVo Gentlepower Lux) at 200.000 rpm for $5 \mathrm{~s}$ under water-cooling and rinsed with copious water.

Group AA: The enamel was roughened using a chairside air-abrasion device (Ronvig, Daugärd, Denmark) where air-borne particle was achieved using $50 \mu \mathrm{m} \mathrm{Al}_{2} \mathrm{O}_{3}$ particles (Korox, Bego, Bremen, Germany) at 2 bar for $5 \mathrm{~s}$ from a distance of approximately $10 \mathrm{~mm}$ in rotating motions. Enamel surfaces were then rinsed with copious water to remove the particle remnants.

The enamel surface on each tooth was divided into 4 quadrants and 3 of 4 quadrants received the conditioning methods in a clockwise sequence (Fig. 2). During conditioning of one quadrant, the remaining quadrants were protected with a Teflon shield (Angst+Pfister AG, Zurich, Switzerland). One operator performed all roughening and bonding procedures (MS). After each conditioning method, digital surface roughness and contact angle measurements were repeated as described above.

The enamel surface in each quadrant was conditioned with etch and rinse adhesive system (Syntac Classic, Ivoclar Vivadent, Schaan, Liechtenstein) according to the manufacturer's recommendations. Firstly, the enamel was etched for $60 \mathrm{~s}$ with $37 \% \mathrm{H}_{3} \mathrm{PO}_{4}$, rinsed for $60 \mathrm{~s}$ and then gently air-dried for $5 \mathrm{~s}$. Then, adhesive resin (Heliobond, Ivoclar Vivadent) was applied with a brush for $20 \mathrm{~s}$, air-thinned for $3 \mathrm{~s}$ and photo-polymerized for $40 \mathrm{~s}$ using an LED polymerization unit (Bluephase, Ivoclar Vivadent) from a constant distance of $2 \mathrm{~mm}$ from the surface. Dual-polymerized resin luting cement (Variolink II, Ivoclar Vivadent) was condensed into polyethylene moulds (inner surface area $1 \mathrm{~mm}^{2}$; height: $4 \mathrm{~mm}$ ) in two increments and photo-polymerized for $40 \mathrm{~s}$ using an LED polymerization unit (Bluephase) from a constant distance of $2 \mathrm{~mm}$ from the surface. The specimens were then stored in distilled water for 24 hours at $37^{\circ} \mathrm{C}$ until experiments.

Microshear ( $\mu$ SBS) test 
Specimens were mounted in the jig of the Universal Testing Machine (Z010, Zwick, Ulm, Germany) and shear force was applied to the adhesive interface until failure occurred. The load was applied to the adhesive interface, as close as possible to the surface of the substrate at a crosshead speed of $0.5 \mathrm{~mm} / \mathrm{min}$. $\mu \mathrm{SBS}(\mathrm{MPa})$ was calculated by dividing the maximum load $(\mathrm{N})$ by the bonding surface area of the resin cement $\left(\mathrm{mm}^{2}\right)$.

Failure analysis and microscopy evaluation

Failure sites were initially observed using an optical microscope (Zeiss Supra V50, Carl Zeiss, Oberkochen, Germany) and classified as follows: Type I: Adhesive failure between the adhesive resin and the enamel; Type Ila: Mixed failure between the adhesive resin and the enamel with less than half of the adhesive remained on the dentin surface; Type Ilb: Mixed failure between the adhesive resin and the enamel with more than half of the adhesive resin remained on the enamel surface; Type III: Cohesive failure in the cement; Type IV: Cohesive failure in the enamel (Fig. 3).

Additionally, in order to observe the structural changes on the enamel after conditoning methods, three further enamel specimens were prepared from each group without and with etching after conditioning. They were first sputter-coated with a $18 \mathrm{~nm}$ thick layer of gold $(80 \%)$ I palladium (20\%) (120 s, 45mA; Balzers SCD 030, Balzers, Liechtenstein) and analyzed using cold field emission Scanning Electrone Microscope (SEM) (LEO 440, Electron Microscopy Ltd, Cambridge, UK). Images were made at $0.2-30 \mathrm{kV}$ at a magnification of $\times 5000$.

Statistical analysis

Data were analyzed using a statistical software package (SPSS Software V.20, Chicago, IL, USA). Kolmogorov-Smirnov and Shapiro-Wilk tests were used to test normal distribution of the data. As the data were normally distributed, 1-way analysis of variance (ANOVA) and Tukey's tests were applied to analyze possible differences between the groups for the parameters of roughness, contact angle and bond strength results. Linear model was applied for group comparisons. $P<0.05$ was considered to be statistically significant in all tests. 


\section{Results}

Surface conditioning method significantly affected the adhesion results $(P<0.001)$, surface roughness $(P=0.017)$ and contact angle $(P<0.001)$. Interaction terms were significant $(P>0.05)$.

AA $(338 \pm 182)$ created significantly higher surface roughness compared to SD $(308 \pm 180)$ and DB $(242 \pm 197)(P<0.05)$. After etching with $37 \% \mathrm{H}_{3} \mathrm{PO}_{4}$, DB $(307 \pm 223)$ resulted in significantly lower roughness than those of SD $(385 \pm 173)$ and AA $(414 \pm 193)(P<0.05)($ Table 1).

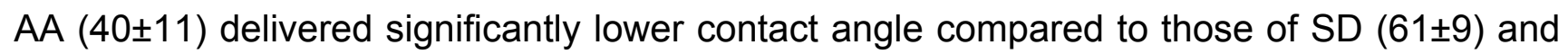
DB (59 \pm 10$)$. After etching with $37 \% \mathrm{H}_{3} \mathrm{PO}_{4}, \mathrm{AA}(42 \pm 10)$ and $\mathrm{DB}(50 \pm 10)$ presented the lowest contact angle $(P<0.05)$ (Table 2$)$.

Mean $\mu$ SBS results (MPa) showed significant difference between the experimental groups $(P=0.011)$ and were in descending order as follows: $D B(20 \pm 8)^{a}<$ SD $(18 \pm 9)^{a}<A A(13 \pm 5)^{b}<C$ $(12 \pm 5)^{b}$ (Table 3).

Failure types were predominantly mixed failure type between the enamel and the resin cement with more than half of the resin remained on the enamel surface (32 to 33 out of 40 ) (Type Ilb) in all groups. Cohesive failure in the enamel was not observed in any of the groups (Fig. 3).

SEM analysis showed that AA group leaves abundant particles on the enamel surface and after $\mathrm{DB}$ and $\mathrm{AA}$, etching could not remove the particles completely and expose the enamel prisms (Figs. 4a-d, 5a-d).

\section{Discussion}

This study was undertaken in order to suggest the most effective mechanical surface conditioning method for removing superficial enamel surface considering morphology, 
wettability parameters and adhesion of resin based cement. Based on the results of this study, since surface conditioning method significantly affected the adhesion results, surface roughness and contact angle, the null hypothesis could be rejected.

Several testing methodologies, (i.e. macroshear, microshear, macrotensile, and microtensile tests) have been suggested for evaluation of the bond strength of resin-based materials to dental substrates. Accordingly, in order to measure the bond strength values between an adherent and a substrate accurately, it is crucial that the bonding interface should be the most stressed region, regardless of the test methodology being employed [13]. In this study, bond strength was tested using $\mu$ SBS test. With this method, inherent problems associated with macroshear test and microtensile tests could be eliminated. While the macroshear test results in cohesive failure of the substrate, not revealing the true bond strength, pre-test failures or misalignment of the specimens are the other problems associated with microtensile test [13]. In $\mu$ SBS test, bonded cylindrical resin cement surface is small enough not to be negatively affected from such factors yielding to more reliable results. One translucent polyethylene mould filled with the cement was bonded on each enamel specimen surface. Through clockwise application of the 3 surface conditioning methods in 4 quadrants of each tooth, the possible inherent morphological changes in enamel on the studied experimental parameters were avoided.

Minimal invasive dental reconstructions or orthodontic appliances are bonded to enamel without removing the enamel with rotating instruments, where the latter in particular does not require any removal of the enamel layer primarily due to iatrogenic reasons as well as the semi-permanent nature of adhesion. Unfortunately, in the orthodontic field, debonding rate particularly in conjunction with lingual retainers bonded on enamel is high [14]. On the other hand, in reconstructive dentistry, especially in the application of sectional veneers in the anterior and occlusal veneers in the posterior regions, certain thickness for the prospective restorative material has to be provided for mechanical durability. Thus, both for this purpose 
and also to remove the possible aprismatic enamel, the top layer of enamel needs to be reduced at different levels.

In this study, clinically relevant minimal invasive surface conditioning methods were used, namely a fine diamond bur, silicone disc and chairside air-abrasion method employing small particle size alumina. Among all methods tested, air-abrasion resulted in the highest roughness compared to SD and DB. Certainly, parameters such as pressure and duration may affect the particle deposition effect on enamel during air-abrasion [15]. Based on preliminary observations, after $5 \mathrm{~s}$, visible effect of air-abrasion was noted on enamel. For this reason, application duration was limited to 10 s. Similarly, after etching with $37 \% \mathrm{H}_{3} \mathrm{PO}_{4}$, air-abrasion again resulted in higher roughness values followed by the silicone disc. In line with this observation, SEM photos verified the fact rough enamel surfaces where both covered the surface with abundant alumina particles and silicone disc remnants. Consequently, the debri did not allow acid attack on enamel even though the surfaces were rinsed with copious water after surface conditioning. It has to be noted that also after diamond bur application, some degree of smear mixture composed of the diamond and hydroxyapatite layer was evident on the enamel surface. Yet, in the majority of the specimens, SEM findings revealed that this smear layer could be removed more effectively from the dental bur treated surfaces compared to air abrasion or silicone disc.

In fact, enamel etching with phosphoric acid selectively dissolves prism cores, with resultant microporosity where the organic matter and inorganic components are altered [16-18]. Accordingly, etching of enamel with phosphoric acid for $60 \mathrm{~s}$ results in a superficially etched zone and sub-surface porous zone. The enamel from the superficial etched zone is permanently lost but the porous zone establishes a mechanical bond to the etched enamel. Although the diamond bur resulted in the lowest roughness, after etching, adhesion results were more favourable in this group. This could be attributed to the exposed enamel prisms being more visible in this group than those of others. 
Roughness can be measured in a number of ways but the most commonly used method in dentistry is the average surface roughness $\left(R_{a}\right)$ value [7]. In this study, a non-contact digital microscope was used to measure the surface roughness. Compared to contact roughness measurement methods such as the stylus of a perthometer, digital measurement systems may suffer from scanning the depth of amorphous structures such as enamel prisms in this case. On the other hand, the tip of the stylus can also damage the enamel surface and for this reason, a digital method was used.

Air-abrasion roughened the enamel surface the most and resulted in lower contact angle among all other conditioning methods before and after $37 \% \mathrm{H}_{3} \mathrm{PO}_{4}$ etching but did not yield to the highest bond strength. This indicates that roughness and wettability parameters could not contribute to increased bond strength in this group.

Surface conditioning or preparation with diamond bur and silicone disc resulted in the highest bond strength followed by the application of $37 \% \mathrm{H}_{3} \mathrm{PO}_{4}$ compared to the application of etching only. Similar results were obtained in a previous study employing macroshear test where enamel was prepared with diamond bur followed by etching with phosphoric acid (19.92 \pm 4.76$)$ [19]. Although both procedures were performed manually, compared to airabrasion, the exposure of enamel prisms were inferior compared to the control group. Yet, interestingly the control groups with the best enamel morphology did not necessarily yield to the highest adhesion results. This could be explained on the groups that the penetration of adhesive resin on the exposed enamel prisms were not ideal reaching the depth of prism cones. The results need to be verified in future studies with other adhesive resins with different viscosities.

The SEM findings did not reveal structural defects in the enamel compared to a previous study [20]. The authors speculated that due to the brittleness of the enamel, this substrate is more prone to defects during debonding that is created during surface preparation $[21,22]$. Since in this study, no cohesive failures in the enamel was noted, it can be stated that the 
achieved mean bond strength did not exceed that of the cohesive strength of the enamel. In this study, even though the highest mean values ranged between 18 and $20 \mathrm{MPa}$, the results did not yield to defects in the enamel after debonding. Thus, these obtained values could be considered clinically safe for particularly orthodontic applications where semi-permanent adhesion is expected, where at the end of the orthodontic treatment, bonded appliances are removed. The high incidence of Type IIb failure types in this study, indicates that the resin cement remnants could be removed after debonding. For restorative applications, perhaps not the bond strength but the quality of margins in relation to the enamel prisms could be of importance to void marginal discoloration. The findings of this study have be verified in clinical applications when evaluating the marginal quality of the bonded reconstructions on enamel after different enamel conditioning or preparation methods.

\section{Conclusions}

From this study, the following could be concluded:

1. Air-abrasion roughened the enamel surface the most and resulted in lower contact angle among all other conditioning methods before and after $37 \% \mathrm{H}_{3} \mathrm{PO}_{4}$ etching but did not yield to the highest bond strength.

2. Mechanical surface conditioning methods followed by the application of $37 \% \mathrm{H}_{3} \mathrm{PO}_{4}$ favourably affected adhesion of resin cement to enamel compared to the application of etching only.

3. Failure types after debonding were mainly mixed failure type between the enamel and the resin cement with more than half of the resin remained on the enamel surface in all groups. Cohesive failure in the enamel was not observed in any of the groups

4. Air-abrasion and silicone disc left abundant debri on the enamel surface that could not be removed after etching, impairing adhesion. Enamel prisms were best exposed in the control group followed by the use of diamond bur. 


\section{Clinical Relevance}

Considering, morphological changes, roughness values, wettability properties, adhesive strength of the resin cement, conditioning enamel surface with fine diamond bur under copious water followed by $37 \% \mathrm{H}_{3} \mathrm{PO}_{4}$ etching could be recommended when bonding minimal invasive reconstructions on superficial enamel.

\section{Acknowledgement}

The authors acknowledge Mr. A. Trottmann, University of Zürich, Center for Dental and Oral Medicine, Zürich, Switzerland, for his assistance with the specimen preparation, Dr. M. Roos and Mr. D. Wiedemeier for their support with the statistical analysis, and Mrs. B. Sener for her help with the SEM images.

\section{Conflict of interest}

The authors did not have any commercial interest in any of the materials used in this study. 


\section{References}

[1] Graber TM, Eliades T, Athanasiou AE. Risk management in orthodontics: Experts' guide to malpractice. Chicago: Quintessence Pub. Co.; 2004.

[2] Hellwig E, Klimek J, Attin T. Einführung in die Zahnerhaltung: Prüfungswissen Kariologie, Endodontologie und Parodontologie; mit 60 Tabellen, ed. 6. Köln: Dt. Ärzte-Verl.; 2013.

[3] Shahabi M, Ahrari F, Mohamadipour H, Moosavi H. Microleakage and shear bond strength of orthodontic brackets bonded to hypomineralized enamel following different surface preparations. J Clin Exp Dent 2014;6:e110-e115.

[4] Lasers in Restorative Dentistry: A Practical Guide. Rome: Springer; 2015. p.3-6.

[5] Schwartz RS. Fundamentals of operative dentistry: A contemporary approach. Quintessence books. Chicago: Quintessence Publ; 1996. p. 209.

[6] Kugel G, Ferrari M. The science of bonding: from first to sixth generation. J Am Dent Assoc 2000;131 Suppl:20S-25S.

[7] Joniot SB, Grégoire GL, Auther AM, Roques YM. Three-dimensional optical profilometry analysis of surface states obtained after finishing sequences for three composite resins. Oper Dent 2000;25:311-15.

[8] Hussain S. Textbook of dental materials. New Delhi: Jaypee; 2004. p.7-9.

[9] Wege HA, Holgado-Terriza JA, Rosales-Leal Jl, Osorio R, Toledano M, Cabrerizo-Vílchez MÁ. Contact angle hysteresis on dentin surfaces measured with ADSA on drops and bubbles. Colloid Surface A 2002;206:469-483.

[10]Oshida $\mathrm{Y}$, Sachdeva R, Miyazaki S. Changes in contact angles as a function of time on some pre-oxidized biomaterials. J Mater Sci: Mater Med 1992;3:306-312. 
[11] Newman GV, Snyder WH, Wilson CE. Acrylic adhesives for bonding attachments to tooth surfaces. Angle Orthodont 1968;38:12-18.

[12] Strom G, Frederiksson M, Stenius P. Kinetics of steady-state wetting. J Colloid Interface Sci 1990;134:107-115.

[13] Della Bona A, Van Noort R. Shear vs. tensile bond strength of resin composite bonded to ceramic. J Dent Res 1995;74:1591-1596.

[14] Lie Sam Foek DJ, Özcan M, Verkerke GJ, Sandham A, Dijkstra PU. Survival of flexible, braided, bonded stainless steel lingual retainers: a historic cohort study. Eur J Orthod 2008;30:199-204.

[15] Özcan M, Raadschelders J, Vallittu P, Lassilla L. Effect of particle deposition parameters on silica coating of zirconia using a chairside air-abrasion device. J Adhes Dent 2013;15:211214.

[16] Retief DH, Woods E, Jamison HC. Effect of cavosurface treatment on marginal leakage in class V composite resin restorations. J Prosthet Dent 1982;47:496-501.

[17] Chung K, Hsu B, Berry T, Hsieh T. Effect of sandblasting on the bond strength of the bondable molar tube bracket. J Oral Rehabil 2001;28:418-424.

[18] Charles A, Senkutvan R, Ramya RS, Jacob S. Evaluation of shear bond strength with different enamel pretreatments: an in vitro study. Ind J Dent Res 2014;25:470-474.

[19] Parhami P, Pourhashemi SJ, Ghandehari M, Mighani G, Chiniforush N. Comparative study of the shear bond strength of flowable composite in permanent teeth treated with conventional bur and contact or non-contact Er:YAG laser. J Lasers in Med Sci 2014;5:140145.

[20] Ferrari M, Goracci C, Sadek F, Eduardo P, Cardoso C. Microtensile bond strength tests: scanning electron microscopy evaluation of sample integrity before testing. Eur J Oral Sci 2002;110:385-391. 
[21] Shimada Y, Tagami J. Effects of regional enamel and prism orientation on resin bonding. Oper Dent 2003;28:20-27.

[22] Sadek FT, Cury AH, Monticelli F, Ferrari M, Cardoso, Paulo E Capel. The influence of the cutting speed on bond strength and integrity of microtensile specimens. Dent Mater 2005;21:1144-1149. 


\section{Captions to figures and tales:}

\section{Figures:}

Fig. 1. Flow-chart showing experimental sequence and allocation of groups.

Fig. 2 Sketch of the sequence of surface conditioning methods applied in 4 quadrants of enamel on incisors clockwise. 1) Non-conditioned enamel acting as the control group; 2) Silicone coated disc (Sof-Lex disc, Black, 3M ESPE); 3) Diamond bur at slow speed and 4) Airborne particle abrasion ( $50 \mu \mathrm{m} \mathrm{Al}_{2} \mathrm{O}_{3}, 2$ bar, $\left.5 \mathrm{~s}\right)$.

Fig. 3 Frequencies of failure modes in percentages. Type I: Adhesive failure between the adhesive resin and the enamel; Type Ila: Mixed failure between the adhesive resin and the enamel with less than half of the adhesive remained on the enamel surface; Type Ilb: Mixed failure between the adhesive resin and the enamel with more than half of the adhesive resin remained on the enamel surface; Type III: Cohesive failure in the cement; Type IV: Cohesive failure in the enamel.

Figs. 4a-d SEM images of a) C, b) $\mathrm{SD}$, c) $\mathrm{DB}$, d) $\mathrm{AA}$ before etching with $37 \% \mathrm{H}_{3} \mathrm{PO}_{4}$ (x5000). Note the rough enamel surfaces especially in the air-abraded group.

Figs. 5a-d SEM images of a) C, b) SD, c) DB, d) AA after etching with $37 \% \mathrm{H}_{3} \mathrm{PO}_{4}(x 5000)$. Note the best enamel prism morphology in the group C followed by DB after etching. After SD, and $\mathrm{AA} 37 \% \mathrm{H}_{3} \mathrm{PO}_{4}$ could not remove the particles completely and expose enamel prisms. 


\section{Tables:}

Table 1. Surface roughness $(\mu \mathrm{m})$ (Mean \pm standard deviation), maximum, minimum and confidence intervals $(95 \%)$ at baseline, after surface conditioning methods, surface conditioning $+37 \% \mathrm{H}_{3} \mathrm{PO}_{4}$ of enamel. C: Non-conditioned enamel acting as the control group; SD: Silicone coated disc (Sof-Lex disc, Black, 3M ESPE); DB: Diamond bur at slow speed and AA: Air-borne particle abrasion (50 $\mu \mathrm{m} \mathrm{Al}_{2} \mathrm{O}_{3}, 2$ bar, $\left.5 \mathrm{~s}\right)$. Different upper-case letters in each column for each condition indicates significant differences $(p<0.05)$.

Table 2. Contact angle $(\theta)$ (Mean \pm standard deviation), maximum, minimum and confidence intervals (95\%) at baseline, after surface conditioning methods, surface conditioning $+37 \%$ $\mathrm{H}_{3} \mathrm{PO}_{4}$ of enamel. C: Non-conditioned enamel acting as the control group; SD: Silicone coated disc (Sof-Lex disc, Black, 3M ESPE); DB: Diamond bur at slow speed and AA: Air-borne particle abrasion (50 $\mu \mathrm{m} \mathrm{Al}_{2} \mathrm{O}_{3}, 2$ bar, $5 \mathrm{~s}$ ). Different upper-case letters in each column for each condition indicates significant differences $(p<0.05)$.

Table 3. Microshear bond strength (MPa) (Mean \pm standard deviation), maximum, minimum and confidence intervals $(95 \%)$ at baseline, after surface conditioning methods, surface conditioning $+37 \% \mathrm{H}_{3} \mathrm{PO}_{4}$ of enamel. C: Non-conditioned enamel acting as the control group; SD: Silicone coated disc (Sof-Lex disc, Black, 3M ESPE); DB: Diamond bur at slow speed and AA: Air-borne particle abrasion (50 $\mu \mathrm{m} \mathrm{Al}_{2} \mathrm{O}_{3}, 2$ bar, $\left.5 \mathrm{~s}\right)$. Different upper-case letters in each column indicates significant differences $(p<0.05)$. 


\section{Figures:}

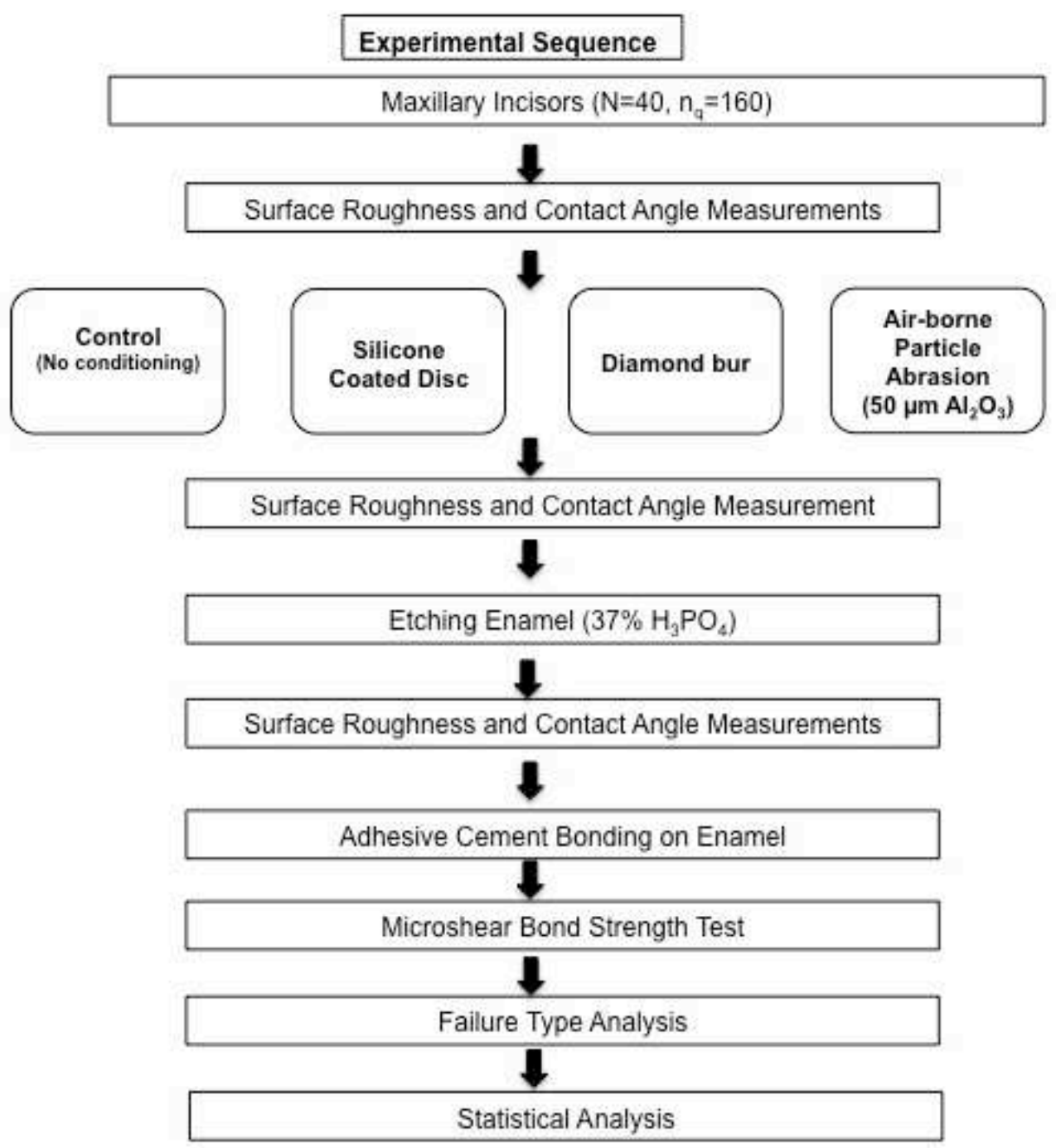

Fig. 1. Flow-chart showing experimental sequence and allocation of groups. 


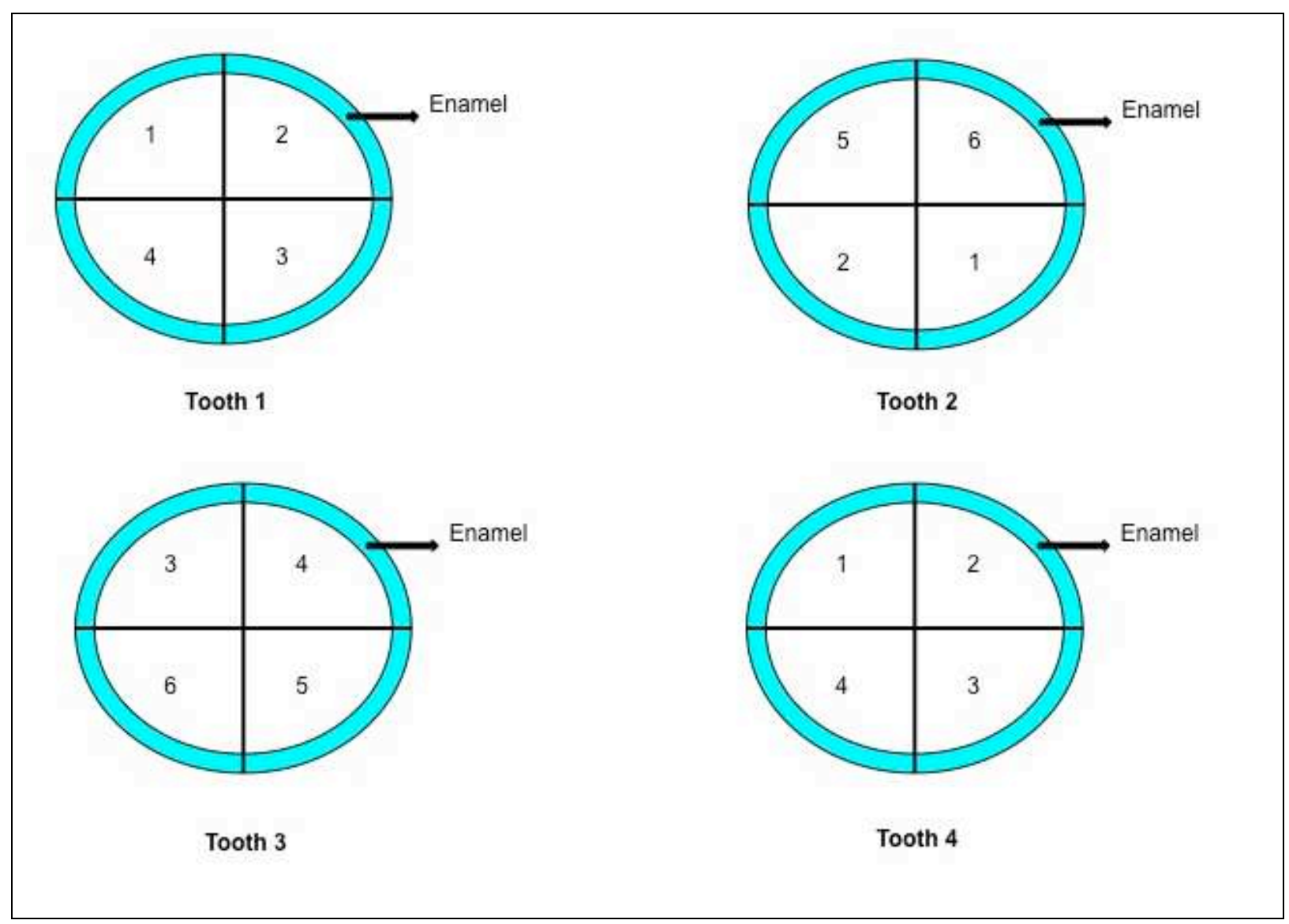

Fig. 2 Sketch of the sequence of surface conditioning methods applied in 4 quadrants of enamel on incisors clockwise. 1) Non-conditioned enamel acting as the control group; 2) Silicone coated disc (Sof-Lex disc, Black, 3M ESPE); 3) Diamond bur at slow speed and 4) Air-borne particle abrasion (50 $\mu \mathrm{m} \mathrm{Al}_{2} \mathrm{O}_{3}, 2$ bar, $5 \mathrm{~s}$ ). 


\section{Failure Types}

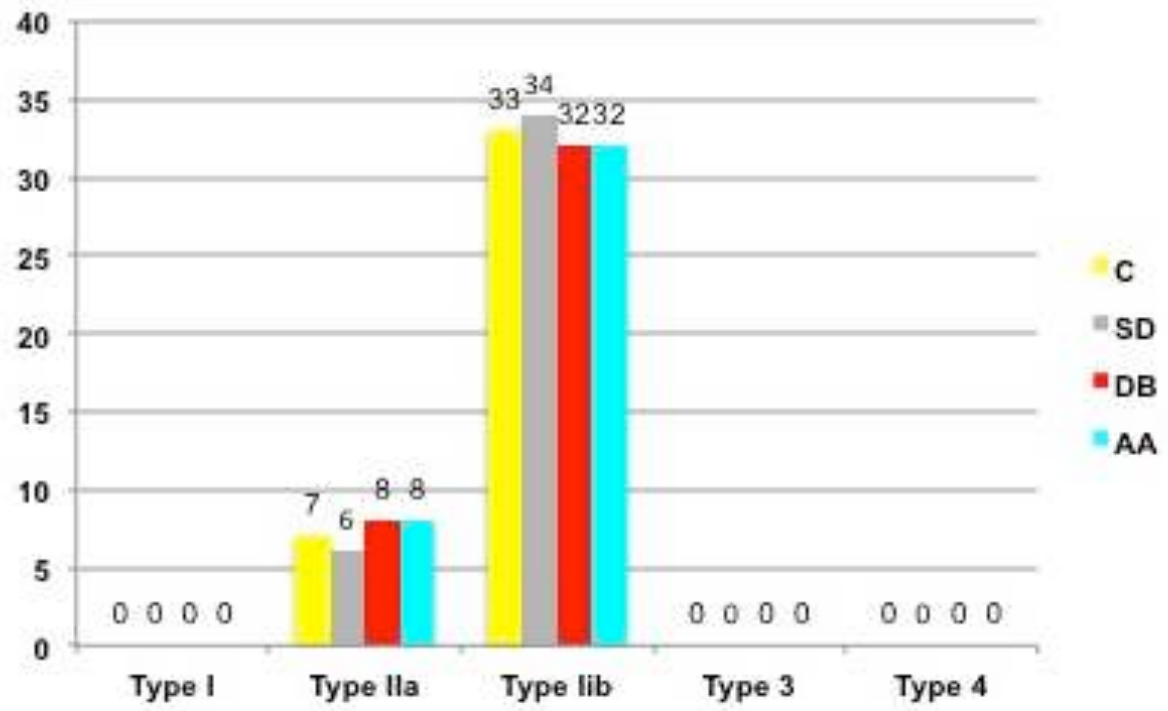

Fig. 3 Frequencies of failure modes in percentages. Type I: Adhesive failure between the adhesive resin and the enamel; Type Ila: Mixed failure between the adhesive resin and the enamel with less than half of the adhesive remained on the enamel surface; Type IIb: Mixed failure between the adhesive resin and the enamel with more than half of the adhesive resin remained on the enamel surface; Type III: Cohesive failure in the cement; Type IV: Cohesive failure in the enamel. 
a

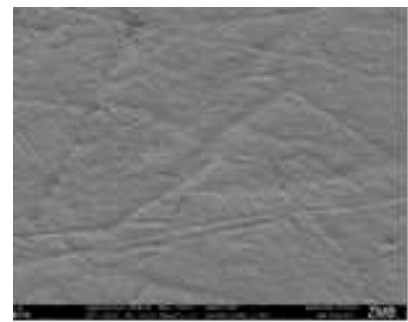

b

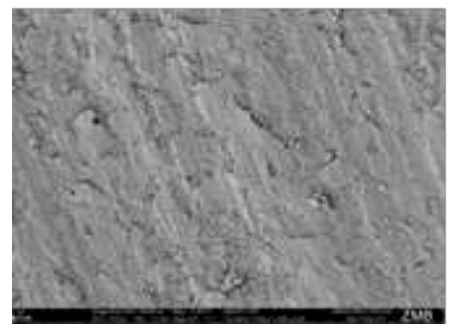

C

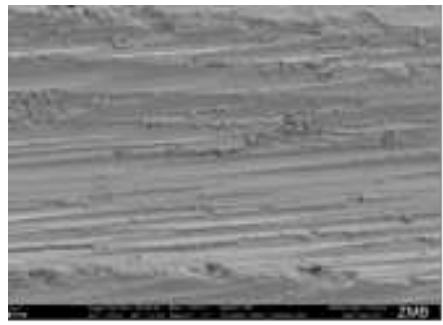

d

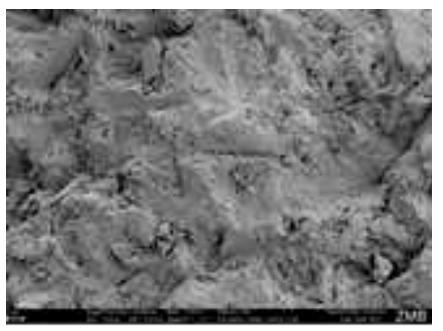

Figs. 4a-d SEM images of a) C, b) SD, c) DB, d) AA before etching with $37 \% \mathrm{H}_{3} \mathrm{PO}_{4}(x 5000)$. Note the rough enamel surfaces especially in the air-abraded group.

a

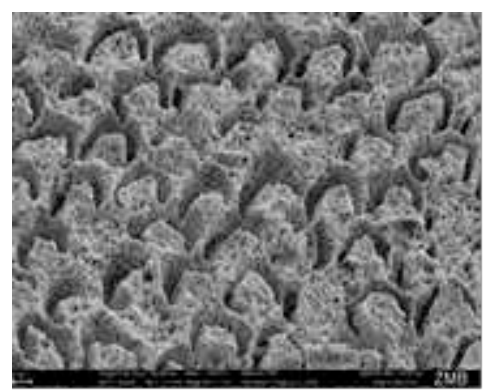

b

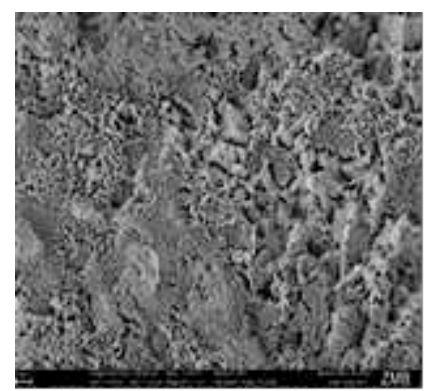

C

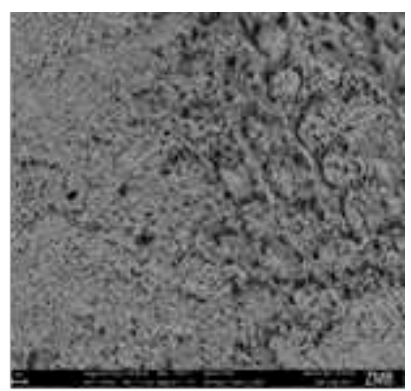

d

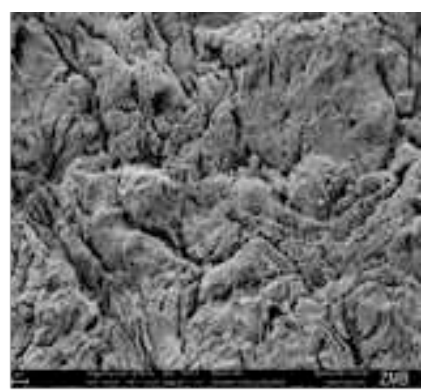

Figs. 5a-d SEM images of a) C, b) SD, c) DB, d) AA after etching with $37 \% \mathrm{H}_{3} \mathrm{PO}_{4}(x 5000)$. Note the best enamel prism morphology in the group $C$ followed by DB after etching. After SD, and AA 37\% $\mathrm{H}_{3} \mathrm{PO}_{4}$ could not remove the particles completely and expose enamel prisms. 


\begin{tabular}{|c|c|c|c|c|c|c|}
\hline \multirow{2}{*}{$\begin{array}{l}\text { Experimental } \\
\text { Groups }\end{array}$} & \multirow[t]{2}{*}{$\mathbf{n}_{\mathbf{q}}$} & \multirow[t]{2}{*}{ Mean (SD) } & \multirow[t]{2}{*}{ Minimum } & \multirow[t]{2}{*}{ Maximum } & \multicolumn{2}{|c|}{ Confidence Interval } \\
\hline & & & & & Lower Bound & Upper Bound \\
\hline \multicolumn{7}{|c|}{ Baseline } \\
\hline C & 10 & $316 \pm 165^{A}$ & 75.9 & 873.1 & 263.659 & 369.780 \\
\hline SD & 10 & $347 \pm 167^{A}$ & 25.1 & 690.9 & 294.404 & 401.309 \\
\hline DB & 10 & $368 \pm 226^{A}$ & 76.7 & 1012.6 & 296.354 & 441.024 \\
\hline AA & 10 & $343 \pm 204^{A}$ & 64.9 & 893.4 & 227.825 & 408.606 \\
\hline \multicolumn{7}{|c|}{ Surface Conditioning } \\
\hline C & 10 & $316 \pm 165^{A}$ & 75.9 & 873.1 & 263.659 & 369.780 \\
\hline SD & 10 & $308 \pm 180^{A}$ & 48.2 & 772.6 & 250.803 & 366.242 \\
\hline DB & 10 & $242 \pm 197^{A, B}$ & 26.3 & 883.3 & 179.537 & 306.123 \\
\hline AA & 10 & $338 \pm 182^{C}$ & 38.6 & 809.9 & 280.249 & 396.981 \\
\hline \multicolumn{7}{|c|}{ Surface Conditioning $+37 \% \mathrm{H}_{3} \mathrm{PO}_{4}$} \\
\hline C & 10 & $452 \pm 235^{\mathrm{A}}$ & 157.2 & 1113.2 & 377.531 & 528.034 \\
\hline SD & 10 & $385 \pm 173^{A}$ & 97.0 & 760.9 & 330.327 & 441.583 \\
\hline DB & 10 & $307 \pm 223^{B}$ & 61.6 & 1016.4 & 235.659 & 378.921 \\
\hline AA & 10 & $414 \pm 193^{A}$ & 78.7 & 880.7 & 352.553 & 476.122 \\
\hline
\end{tabular}

Table 1. Surface roughness $(\mu \mathrm{m})$ (Mean \pm standard deviation), maximum, minimum and confidence intervals (95\%) at baseline, after surface conditioning methods, surface conditioning $+37 \% \mathrm{H}_{3} \mathrm{PO}_{4}$ of enamel. C: Nonconditioned enamel acting as the control group; SD: Silicone coated disc (Sof-Lex disc, Black, 3M ESPE); DB: Diamond bur at slow speed and AA: Air-borne particle abrasion (50 $\mu \mathrm{m} \mathrm{Al}_{2} \mathrm{O}_{3}, 2$ bar, $5 \mathrm{~s}$ ). Different upper-case letters in each column for each condition indicates significant differences $(p<0.05)$. 


\begin{tabular}{|c|c|c|c|c|c|c|}
\hline \multirow{2}{*}{$\begin{array}{l}\text { Experimental } \\
\text { Groups }\end{array}$} & \multirow[t]{2}{*}{$\mathbf{n}_{\mathrm{q}}$} & \multirow[t]{2}{*}{ Mean (SD) } & \multirow[t]{2}{*}{ Minimum } & \multirow[t]{2}{*}{ Maximum } & \multicolumn{2}{|c|}{ Confidence Interval } \\
\hline & & & & & Lower Bound & Upper Bound \\
\hline \multicolumn{7}{|c|}{ Baseline } \\
\hline C & 10 & $66 \pm 12^{A}$ & 38.3 & 87.1 & 62.575 & 70.398 \\
\hline SD & 10 & $65 \pm 12^{A}$ & 35.1 & 86.2 & 61.083 & 69.082 \\
\hline DB & 10 & $64 \pm 13^{A}$ & 33.0 & 84.8 & 60.609 & 68.961 \\
\hline AA & 10 & $67 \pm 13^{A}$ & 34.0 & 95.5 & 62.953 & 71.474 \\
\hline \multicolumn{7}{|c|}{ Surface Conditioning } \\
\hline C & 10 & $66 \pm 12^{A}$ & 38.3 & 87.1 & 62.575 & 70.398 \\
\hline SD & 10 & $61 \pm 9^{A}$ & 39.4 & 86.6 & 58.520 & 64.573 \\
\hline DB & 10 & $59 \pm 10^{A}$ & 34.1 & 84.7 & 55.839 & 62.776 \\
\hline AA & 10 & $40 \pm 11^{\mathrm{B}}$ & 16.5 & 61.6 & 36.468 & 43.937 \\
\hline \multicolumn{7}{|c|}{ Surface Conditioning $+37 \% \mathrm{H}_{3} \mathrm{PO}_{4}$} \\
\hline C & 10 & $55 \pm 12^{\mathrm{A}}$ & 28.2 & 83.8 & 51.600 & 59.885 \\
\hline SD & 10 & $58 \pm 8^{A}$ & 40.9 & 73.7 & 55.951 & 61.288 \\
\hline DB & 10 & $50 \pm 10^{A}$ & 26.9 & 70.8 & 46.734 & 53.656 \\
\hline AA & 10 & $42 \pm 10^{B}$ & 18.9 & 81.2 & 38.699 & 45.596 \\
\hline
\end{tabular}

Table 2. Contact angle $(\theta)$ (Mean \pm standard deviation), maximum, minimum and confidence intervals $(95 \%)$ at baseline, after surface conditioning methods, surface conditioning $+37 \% \mathrm{H}_{3} \mathrm{PO}_{4}$ of enamel. C: Non-conditioned enamel acting as the control group; SD: Silicone coated disc (Sof-Lex disc, Black, 3M ESPE); DB: Diamond bur at slow speed and AA: Air-borne particle abrasion (50 $\mathrm{mm} \mathrm{Al}_{2} \mathrm{O}_{3}, 2$ bar, $\left.5 \mathrm{~s}\right)$. Different upper-case letters in each column for each condition indicates significant differences $(p<0.05)$. 


\begin{tabular}{|l|l|c|c|c|c|c|}
\hline $\begin{array}{l}\text { Experimental } \\
\text { Groups }\end{array}$ & $\mathbf{n}_{\mathbf{q}}$ & Mean (SD) & Minimum & Maximum & \multicolumn{2}{|c|}{ Confidence Interval } \\
\cline { 4 - 7 } & & & & & Lower Bound & Upper Bound \\
\hline C & 10 & $12 \pm 5^{\mathrm{A}}$ & 5.3 & 24.7 & 11.204 & 14.446 \\
\hline SD & 10 & $18 \pm 9^{\mathrm{B}}$ & 5.6 & 51.0 & 15.861 & 21.974 \\
\hline AB & 10 & $20 \pm 8^{\mathrm{B}}$ & 8.1 & 50.4 & 18.032 & 23.713 \\
\hline
\end{tabular}

Table 3. Microshear bond strength ( $\mathrm{MPa}$ ) (Mean \pm standard deviation), maximum, minimum and confidence intervals (95\%) at baseline, after surface conditioning methods, surface conditioning $+37 \% \mathrm{H}_{3} \mathrm{PO}_{4}$ of enamel. C: Non-conditioned enamel acting as the control group; SD: Silicone coated disc (Sof-Lex disc, Black, 3M ESPE); DB: Diamond bur at slow speed and AA: Air-borne particle abrasion (50 $\mu \mathrm{m} \mathrm{Al} \mathrm{O}_{3}, 2$ bar, $\left.5 \mathrm{~s}\right)$. Different uppercase letters in each column indicates significant differences $(p<0.05)$. 
